\title{
PERMODELAN CURAH HUJAN BULANAN DI KOTA BENGKULU DENGAN SEASONAL AUTOREGRESSIVE INTEGRATED MOVING AVERAGE (SARIMA) \\ Studi Kasus: Stasiun Klimatologi di Bengkulu
}

\author{
MODELLING MONTHLY RAINFALL IN BENGKULU CITY USING \\ SEASONAL AUTOREGRESSIVE INTEGRATED MOVING AVERAGE \\ (SARIMA) \\ Case Study: Climatology Station In Bengkulu
}

\author{
Herlin Fransiska ${ }^{1}$, Pepi Novianti², Dian Agustina² \\ Jurusan Matematika FMIPA Universitas Bengkulu ${ }^{1,2,3}$ \\ Pematang Gubernur, Bengkulu \\ E-mail: hfransiska@unib.ac.id
}

\begin{abstract}
ABSTRAK
Hujan adalahn unsur iklim yang sangat penting karena curah hujan berpengaruh terhadap perubahan iklim dan iklim berpengaruh terhadap banyak sektor seperti pertanian dan perikanan. Hal ini menjadikan permodelan curah hujan sangat penting untuk dikaji. Kota Bengkulu terdiri dari dua musim (Hujan dan Kemarau) dan juga memiliki cuaca yang sangat cepat berubah karena letak geografis Bengkulu yang berbatasan dengan Samudra Hindia yang berakibat jika terjadi tekanan rendah di Samudra Hindia maka Bengkulu akan mengalami hujan yang tinggi. Curah hujan yang terdiri dari dua musin dan terjadi secara berulang, sehingga curah hujan termasuk kedalam pola monsunal yang dicirikan oleh tipe curah hujan yang bersifat unimodial (satu puncak musim hujan). Jika menggunakan data curah hujan masa lalu maka metode yang tepat untuk memodelkan curah hujan adalah metode Seasonal Autoregressive Integrated Moving Average (SARIMA). Tujuan yang ingin dicapai dalam penelitian ini adalah mengetahui model SARIMA yang terbentuk pada data curah hujan mingguan Kota Bengkulu. Hasil yang diperoleh model SARIMA $(0,1,1)(0,1,1)^{12}$ merupakan model curah hujan bulanan di Kota Bengkulu yang terbaik dengan AIC 207,40 dan SBC 215,06 . Model ini selanjutnya dapat digunakan untuk peramalan.
\end{abstract}

Kata Kunci: Curah Hujan, Kota Bengkulu, SARIMA

\section{ABSTRACT}

Rain is a very important climate element because rainfall effects climate change and climate effects of many sectors such as agriculture and fisheries. This makes rainfall modeling very important to study. Bengkulu City consists of two seasons (Rain and Dry) and the city of Bengkulu has very fast-changing weather because Bengkulu's geographical location bordering the Indian Ocean that resulted if there is low pressure in the Indian Ocean Bengkulu will experience high rainfall. Rainfall consists of two monsoons and rainfall occurs repeatedly, so that rainfall has a monsoonal pattern characterized by a type of unimodal rainfall (one peak of the rainy season). If using historical rainfall data then the method for modeling rainfall is the Seasonal Autoregressive Integrated Moving Average (SARIMA) method. This research aims to find out the SARIMA model for monthly rainfall in Bengkulu City. The monthly rainfall model in Bengkulu City is SARIMA $(0,1,1)$ $(0,1,1)^{12}$ with AIC 205,80 and SBC 210,91 . This model can then be used for forecasting.

Keywords: Rainfall, Bengkulu City, SARIMA

\section{PENDAHULUAN}

Hujan merupakan salah satu fenomena alam yang terdapat dalam siklus hidrologi dan unsur iklim yang sangat penting karena curah hujan memiliki pengaruh yang sangat besar terhadap perubahan iklim (Agus, Samuel Haryanto, Puspitaningrum and Ernawati, 2015). Intensitas curah hujan yang besar berarti hujan lebat, sangat berbahaya karena berdampak buruk pada aktivitas kehidupan masyarakat seperti: banjir dan longsor. Hal ini akan berefek negatif terhadap berbagai sektor seperti pertanian, perikanan, pariwisata dan transportasi. Di indonesia terdapat dua musim yaitu musim hujan dan musim kemarau. Kota Bengkulu merupakan kota yang memiliki dua musim 
namun juga memiliki cuaca yang sangat cepat berubah, karena letak geografis Bengkulu yang berbatasan dengan Samudra Hindia. Hal ini menyebabkan jika terjadi tekanan rendah di Samudra Hindia maka Bengkulu akan mengalami hujan yang tinggi. Sehingga Kota Bengkulu menjadi Kota dengan curah hujan yang tinggi dan sifat sangat basah. Salah satu dampak buruk curah hujan yang sangat tinggi di Kota Bengkulu adalah banjir bandang pada tahun 2019. Hal ini menjadikan informasi curah hujan di Kota Bengkulu sangat penting untuk diketahui.

Permodelan data rata-rata curah hujan bulanan di Kota Bengkulu dapat dilakukan dengan menggunakan metode Seasonal Autoregressive Integrated Moving Average (SARIMA) jika permodelan menggunakan data time series univariat dan memiliki pola musiman. Menurut Suhartono (2011), peramalan menggunakan data time series univariat yang pertama diperkenalkan oleh Box dan Jenkins pada tahun 1976 adalah Autoregressive Integrated Moving Average (ARIMA) dan masih menjadi permodelan yang paling populer untuk peramalan. Model ini berasal dari model Autoregressive (AR), model Moving Average (MA) dan kombinasi AR dan MA, model ARMA. Pada kasus dimana terdapat komponen musiman dalam model, maka model ini disebut sebagai model SARIMA (Suhartono, 2011).

Beberapa penelitian tentang curah hujan yaitu Pemodelan deret waktu dan peramalan curah hujan pada dua belas stasiun di bogor oleh Maulana, 2018 diperoleh model deret waktu terbaik untuk 12 stasiun di bogor: $\operatorname{ARIMA}(1,1,1), \operatorname{ARIMA}(1,1,0), \operatorname{DAN} \operatorname{ARIMA}(3,1,0)$ dan peramalan data curah hujan dengan Seasonal Autoregressive Integrated Moving Average (SARIMA) dengan deteksi outlier sebagai upaya optimalisasi produksi pertanian di Kabupaten Mojokerto oleh Huda et al., 2012 diperoleh bahwa Metode ini mampu mengakomodasi data curah hujan yang memiliki fluktuasi tinggi dan nilai ekstrim.

\section{METODE}

Objek penelitian yang akan diamati adalah Kota Bengkulu. Variabel yang digunakan adalah ratarata curah hujan Bulanan di Kota Bengkulu. Tahapan penelitian ini meliputi kegiatan, pertama Pengumpulan data. Dalam penelitian ini akan digunakan data rata-rata curah hujan bulanan 01 Januari 2008-31 Oktober 2017 di Kota Bengkulu. Sumber data berasal dari BMKG Bengkulu. Data dari BMKG berupa data harian dari beberapa stasiun yang kemudian di konversikan ke data bulanan dan dilakukan perhitungan rata-rata curah hujan bulanan kota Bengkulu. Kedua Eksplorasi Data. Tujuan dari eksplorasi data adalah untuk memberikan deskripsi secara umum terhadap data ratarata curah hujan Bulanan di Kota Bengkulu. Ketiga pemodelan dengan metode Box-Jenkins. Membangun model SARIMA akan dilakukan tahapan permodelan yaitu uji stasioneritas dan penanganannya kemudian identifikasi model, pendugaan parameter model, dan diagnostik model, serta overfitting. Keempat pemilihan Model Terbaik. Dari beberapa model SARIMA yang memenuhi uji signifikasi parameter dan asumsi residual (white noise dan kenormalan), akan dipilih model terbaik berdasarkan kriteria AIC dan SBC. Terakhir peramalan. Peramalan menggunakan model terbaik yang terpilih.

Bentuk umum model SARIMA $(p, d, q)(P, D, Q)^{s}$ yaitu(Geurts, Box and Jenkins, 2006):

$\phi_{p}(B) \Phi_{p}\left(B^{s}\right)(1-B)^{d}\left(1-B^{S}\right)^{D} Z_{t}=\theta_{p}(B) \Theta_{p}\left(B^{S}\right) a_{t}$

dimana:

$\phi_{p}(B)=1-\phi_{1} B-\phi_{2} B^{2}-\cdots-\phi_{p} B^{p}$

$\Phi_{P}\left(B^{S}\right)=1-\Phi_{1} B-\Phi_{2} B^{2}-\cdots-\Phi_{P} B^{P S}$

$\theta_{q}(B)=1-\theta_{1} B-\theta_{2} B^{2}-\cdots-\theta_{q} B^{q}$

$\Theta_{Q}\left(B^{S}\right)=1-\Theta_{1} B-\Theta_{2} B^{2}-\cdots-\Theta_{Q} B^{Q S}$.

Dengan $\phi$ dan $\Phi$ adalah parameter autoregresif (AR) komponen non musiman dan musiman, masing-masing; $\theta$ dan $\Theta$ adalah parameter moving average (MA) komponen non-musiman dan musiman, masing-masing; $\mathrm{B}$ adalah operator Backward, $B\left(Z_{t}\right)=Z_{t-1},(1-B)^{d}$ adalah banyaknya pembedaan non-musiman dan $\left(1-B^{S}\right)^{D}$ adalah banyaknya pembedaan musiman; $\alpha_{t}$ adalah 
variabel acak yang didistribusikan secara independen; $\mathrm{P}$ dan $\mathrm{p}$ orde komponen $\mathrm{AR}$; $\mathrm{Q}$ dan $\mathrm{q}$ orde komponen MA; $D$ dan $d$ adalah banyaknya pembedaan, dan biasanya disingkat SARIMA $(p, d, q)$ $(P, D, Q)^{S}$ (Tadesse and Dinka, 2017).

Tahapan permodelan dengan metode Box-Jenkins ialah:

1. Membuat plot data deret waktu (time series plot), ACF dan PACF.

2. Menguji kestasioneran data dengan melihat plot data deret waktu (time series plot), plot ACF, plot Box-cox dan melakukan uji akar unit menggunakan uji ADF.

3. Melakukan transformasi data yaitu dengan menggunakan metode transformasi Box-Cox apabila data yang digunakan tidak stasioner dalam varian. Melakukan pembedaan (differencing) pada data apabila data yang digunakan tidak stasioner dalam rata-rata. Selanjutnya megecek kestasioneran data yang telah di transformasi ataupun pembedaan (differencing). Tahapan ini dilakukan hingga data stasioner.

4. Menetapkan model dugaan sementara. Menentukan orde model dengan melihat plot ACF serta PACF data yang telah stasioner.

5. Melakukan pendugaan parameter kemudian diuji signifikan parameter model dengan menggunakan uji $t$ atau melihat nilai $p$-value.

6. Melakukan pemeriksaan diagnostik untuk melihat residual model telah memenuhi asumsi sifat white noise dan berdistribusi normal.

7. Melakukan pemilihan model terbaik dengan menggunakan beberapa kriteria pemilihan model terbaik dengan melihat nilai AIC dan SBC. Kriteria pemilihan model terbaik ini dilakukan apabila terdapat lebih dari satu model yang memenuhi syarat yaitu yang memenuhi signifikasin parameter (langkah 5) dan yang memenuhi asumsi (langkah 6).

8. Melakukan overfitting dengan cara meningkatkan orde $p, q, P$, dan $Q$ dari model dugaan sementara sehingga diperoleh beberapa model dengan tetap melihat model yang memenuhi signifikansi parameter dan asumsi residual model.

9. Memilih model terbaik berdasarkan seluruh tahapan yang telah dilakukan.

10. Melakukan peramalan dengan menggunakan model terbaik.

Dalam menentukan suatu model peramalan yang ingin digunakan maka dilakukan evaluasi terhadap model tersebut. Ada dua cara evaluasi model peramalan yang dapat dilakukan, yaitu menggunakan kriteria informasi dan kriteria standar. Kriteria informasi merupakan kriteria untuk menilai kualitas model menggunakan model statistik dari suatu parameter. Kriteria Informasi Akaike (AIC) dan Kriteria Informasi bayesian (SBC). Kritera informasi Akaike (AIC) didefenisikan sebagai: $A I C(M)=2 k-\log L$ dan $\quad S B C(M)=2 k \log n-\log L$, dengan: $\mathrm{k}=\mathrm{jumlah}$ parameter; $\mathrm{L}$ =kemungkinan maksimum; $\mathrm{n}=$ jumlah sampel (Tadesse and Dinka, 2017).

\section{HASIL DAN PEMBAHASAN}

Besarnya curah hujan bulanan di Kota Bengkulu sangat bervariasi dan pola rata-rata curah hujan bulanan di Kota Bengkulu berfluktuatif disetiap bulannya, dengan rata-rata curah hujan bulanan minimum terjadi pada Bulan Oktober 2015 sebesar 0,167 mm dan terbesar pada November 2014 yaitu $21 \mathrm{~mm}$.

Langkah awal dalam permodelan data univariat time series ialah uji stasioneritas data. Uji dapat dilihat dari plot Box-Cox untuk ragam dan uji ADF untuk rataan. Plot Box-Cox menunjukkan bahwa data belum stasioner terhadap ragam dan dan uji ADF menunjukkan bahwa data belum stasioner terhadap rata-rata sehingga dilakukan transformasi dan differencing. Sesuai dengan nilai lamda maka transformasi yang dilakukan ialah transformasi log. Kemudian, data tersebut dilakukan uji stasioneritas pada rataan dan diperoleh bahwa belum stasioner terhadap rata-rata untuk nonmusiman dengan nilai signifikansi yang lebih besar dari taraf signifikansi $5 \%$ ( $\mathrm{p}$-value $>\alpha=0.05$ ) yaitu 0.1610 dan nilai signifikansi musiman $(s=12)$ sebesar 0.7342 yang berarti data belum stasioner sehingga perlu dilakukan pembedaan (differencing) pada lag non-musiman dan lag musiman sehingga di proleh data stasioner terhadap rataan. Setelah dilakukan pembedaan diperoleh plot ACF dan PACF sebagai berikut: 


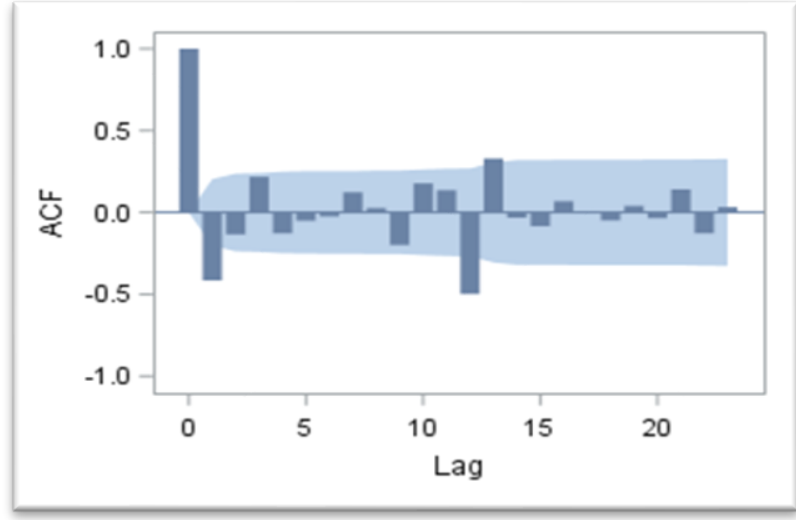

a.

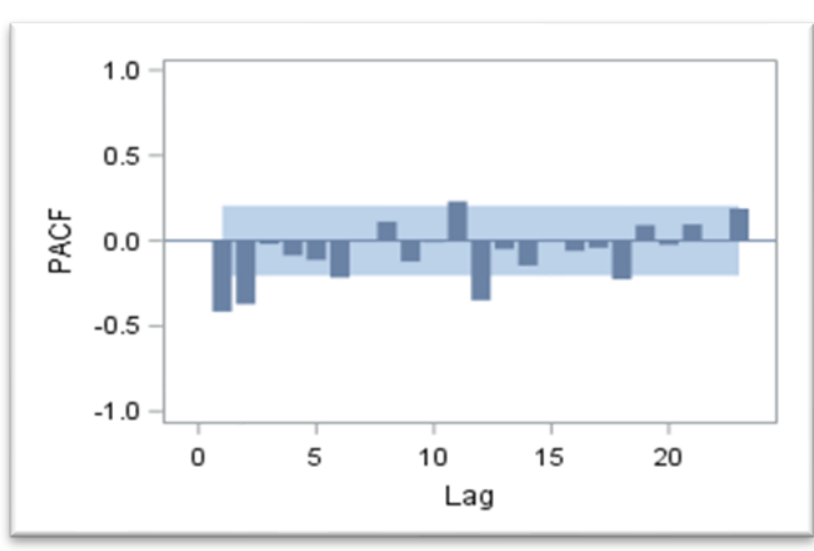

b.

Gambar 1. a. Plot ACF dan b. PACF Data Rata-rata Curah Hujan Bulanan di Kota Bengkulu

Pot ACF (a) menunjukkan bahwa untuk non musiman signifikan pada lag-1 dan untuk musiman pada lag-12. Berdasarkan plot PACF (b) menunjukkan bahwa untuk non-musiman signifikan di lag1, lag-2, lag-6, lag-11, lag-12 dan lag-18. Dalam menentukan model awal, sselain melihat lag yang signifikan juga harus memperhatikan perinsip parsimoni yang berarti mengandung sesedikit mungkin parameter sehingga model lebih stabil. Dengan demikian,identifikasi model dugaan sementara untuk data ini adalah SARIMA $(0,1,1)(0,1,1)^{12}, \operatorname{SARIMA}(1,1,0)(1,1,0)^{12}$, SARIMA $(2,1,0)(0,1,1)^{12}$, SARIMA $(2,1,0)(1,1,0)^{12}$, SARIMA $(1,1,1)(0,1,1)^{12}$, SARIMA $(1,1,1)(1,1,0)^{12}$, SARIMA $(2,1,1)(0,1,1)^{12}$, SARIMA $(1,1,1)(1,1,0)^{12}$, SARIMA $(1,1,1)(1,1,1)^{12}$ dan SARIMA $(2,1,1)(1,1,1)^{12}$.

Selanjutnya melakukan pendugaan parameter model awal, diperoleh sbb:

Tabel 1. Pendugaan Parameter Model Sementara

\begin{tabular}{|c|c|c|c|c|c|c|}
\hline Model & Parameter & Estimate & p-value & AIC & SBC & Keterangan \\
\hline \multirow{2}{*}{$\begin{array}{c}\text { SARIMA } \\
(0,1,1)(0,1,1)^{12}\end{array}$} & $\mathrm{MA}(1)$ & 0,75754 & $<0.001$ & \multirow[t]{2}{*}{205,7969} & \multirow[t]{2}{*}{210,9047} & \multirow{2}{*}{$\begin{array}{c}\text { Model } \\
\text { Signifikan }\end{array}$} \\
\hline & $\operatorname{SMA}(1)$ & 0,13035 & $<0.001$ & & & \\
\hline \multirow{2}{*}{$\begin{array}{c}\text { SARIMA } \\
(1,1,0)(1,1,0) \\
12\end{array}$} & $\mathrm{AR}(1)$ & $-0,36692$ & $<0.001$ & \multirow[t]{2}{*}{232,0178} & \multirow[t]{2}{*}{237,1256} & \multirow{2}{*}{$\begin{array}{c}\text { Model } \\
\text { Signifikan }\end{array}$} \\
\hline & $\operatorname{SAR}(1)$ & $-0,61393$ & $<0.001$ & & & \\
\hline \multirow{3}{*}{$\begin{array}{c}\text { SARIMA } \\
(2,1,0)(0,1,1) \\
12\end{array}$} & $\operatorname{AR}(1)$ & $-0,57297$ & $<0.001$ & \multirow[t]{3}{*}{209,7744} & \multirow[t]{3}{*}{217,4361} & \multirow{3}{*}{$\begin{array}{c}\text { Model } \\
\text { Signifikan }\end{array}$} \\
\hline & $\mathrm{AR}(2)$ & $-0,42055$ & $<0.001$ & & & \\
\hline & $\operatorname{SMA}(1)$ & 0,77407 & $<0.001$ & & & \\
\hline \multirow{3}{*}{$\begin{array}{c}\text { SARIMA } \\
(2,1,0)(1,1,0) \\
12\end{array}$} & $\mathrm{AR}(1)$ & $-0,52744$ & $<0.001$ & \multirow[t]{3}{*}{218,7835} & \multirow[t]{3}{*}{226,4451} & \multirow{3}{*}{$\begin{array}{c}\text { Model } \\
\text { Signifikan }\end{array}$} \\
\hline & $\mathrm{AR}(2)$ & $-0,40404$ & $<0.001$ & & & \\
\hline & $\operatorname{SAR}(1)$ & $-0,58111$ & $<0.001$ & & & \\
\hline \multirow{3}{*}{$\begin{array}{c}\text { SARIMA } \\
(1,1,1)(0,1,1) \\
12\end{array}$} & $\mathrm{AR}(1)$ & 0,12265 & 0,3433 & \multirow[t]{3}{*}{207,0561} & \multirow[t]{3}{*}{214,7177} & \multirow{3}{*}{$\begin{array}{l}\text { Model Tidak } \\
\text { Signifikan }\end{array}$} \\
\hline & $\mathrm{MA}(1)$ & 0,81932 & $<0.001$ & & & \\
\hline & $\operatorname{SMA}(1)$ & 0,80653 & $<0.001$ & & & \\
\hline \multirow{3}{*}{$\begin{array}{c}\text { SARIMA } \\
(1,1,1)(1,1,0) \\
12\end{array}$} & $\operatorname{AR}(1)$ & 0,18993 & 0,17 & \multirow[t]{3}{*}{216,8399} & \multirow[t]{3}{*}{224,5015} & \multirow{3}{*}{$\begin{array}{l}\text { Model Tidak } \\
\text { Signifikan }\end{array}$} \\
\hline & $\mathrm{MA}(1)$ & 0,8113 & & & & \\
\hline & $\operatorname{SAR}(1)$ & $-0,59859$ & & & & \\
\hline \multirow{5}{*}{$\begin{array}{c}\text { SARIMA } \\
(2,1,1)(0,1,1) \\
12\end{array}$} & $\operatorname{AR}(1)$ & 0,05405 & 0,7117 & \multirow[t]{4}{*}{208,5908} & \multirow[t]{4}{*}{218,8063} & \multirow{4}{*}{$\begin{array}{l}\text { Model Tidak } \\
\text { Signifikan }\end{array}$} \\
\hline & $\operatorname{AR}(2)$ & $-0,10289$ & 0,4112 & & & \\
\hline & $\mathrm{MA}(1)$ & 0,74394 & $<0.001$ & & & \\
\hline & $\operatorname{SMA}(1)$ & 0,80664 & $<0.001$ & & & \\
\hline & $\operatorname{AR}(1)$ & $-0,08317$ & 0,5373 & 218,5776 & 228,7931 & \\
\hline
\end{tabular}




\begin{tabular}{|c|c|c|c|c|c|c|}
\hline \multirow{3}{*}{$\begin{array}{c}\text { SARIMA } \\
(2,1,1)(1,1,0) \\
12\end{array}$} & $\operatorname{AR}(2)$ & $-0,59683$ & $<0.001$ & & & \multirow{3}{*}{$\begin{array}{c}\text { Model Tidak } \\
\text { Signifikan }\end{array}$} \\
\hline & $M A(1)$ & 0,74171 & $<0.001$ & & & \\
\hline & $\operatorname{SAR}(1)$ & $-0,59685$ & $<0.001$ & & & \\
\hline \multirow{4}{*}{$\begin{array}{c}\text { SARIMA } \\
(1,1,1)(1,1,1)\end{array}$} & $\operatorname{AR}(1)$ & 0,13336 & 0,3128 & \multirow[t]{4}{*}{208,4995} & \multirow[t]{4}{*}{218,715} & \multirow{4}{*}{$\begin{array}{c}\text { Model Tidak } \\
\text { Signifikan }\end{array}$} \\
\hline & $\mathrm{MA}(1)$ & 0,82057 & $<0.001$ & & & \\
\hline & $\operatorname{SAR}(1)$ & $-0,16331$ & $-0,4155$ & & & \\
\hline & SMA(1) & 0,65258 & 0,0009 & & & \\
\hline \multirow{5}{*}{$\begin{array}{c}\text { SARIMA } \\
(2,1,1)(1,1,1) \\
12\end{array}$} & $\operatorname{AR}(1)$ & 0,06707 & 0,6523 & \multirow[t]{5}{*}{209,9913} & \multirow[t]{5}{*}{222,7607} & \multirow{5}{*}{$\begin{array}{l}\text { Model Tidak } \\
\text { Signifikan }\end{array}$} \\
\hline & $\operatorname{AR}(2)$ & $-0,10492$ & 0,409 & & & \\
\hline & $\mathrm{MA}(1)$ & 0,74635 & $<0.001$ & & & \\
\hline & $\operatorname{SAR}(1)$ & $-0,16604$ & 0,4079 & & & \\
\hline & SMA(1) & 0,65231 & 0,0009 & & & \\
\hline
\end{tabular}

Berdasarkan tabel 1, diperoleh empat (4) model yang semua parameter modelnya signifikan yaitu model SARIMA $(0,1,1)(0,1,1)^{12}$, SARIMA $(1,1,0)(1,1,0){ }^{12}$, SARIMA $(2,1,0)(0,1,1){ }^{12}$ dan SARIMA $(2,1,0)(1,1,0)^{12}$.

Keempat model yang signifikan tersebut selanjutnya dilakukan uji diagnostik yaitu uji asumsi white noise dan uji kenormalan, diperoleh bahwa model SARIMA $(0,1,1)(0,1,1)^{12}$, SARIMA $(2,1,0)(0,1,1){ }^{12}$ dan SARIMA $(2,1,0)(1,1,0){ }^{12}$ memenuhi asumsi white noise sedangkan SARIMA $(1,1,0)(1,1,0){ }^{12}$ tidak memenuhi asumsi white noise. Sedangkan pada asumsi kenormalan menunjukkan bahwa ke-empat model memenuhi. Berdasarkan dua uji tersebut maka model yang layak ialah model yang memenuhi kedua asumsi yaitu SARIMA $(0,1,1)(0,1,1)^{12}$, SARIMA $(2,1,0)(0,1,1)^{12}$ dan SARIMA $(2,1,0)(1,1,0)^{12}$.

Ketiga model yang memenuhi uji signifikansi parameter, uji white noise dan uji kenormalan selanjutnya dilakukan overfitting, diharapkan terdapat model akhir yang memenuhi dan mampu memodelkan dengan lebih baik namun ternyata tidak ada model yang parameternya signifikan. Sehingga hanya tiga model tersebut yang layak digunakan. Untuk memperoleh model terbaik dari ketiga model tersebut, dilihat nilai kriteria AIC dan nilai SBC yang dapat dilihat pada tabel 1 . Nilai kriteria AIC dan SBC terkecil ialah model SARIMA $(0,1,1)(0,1,1)^{12}$ dengan AIC 205,80 and SBC 210,91 . Sehingga, model SARIMA $(0,1,1)(0,1,1)^{12}$ menjadi model terbaik yang dapat digunakan untuk peramalan curah hujan. Hasil ramalan diperoleh sebagai berikut:

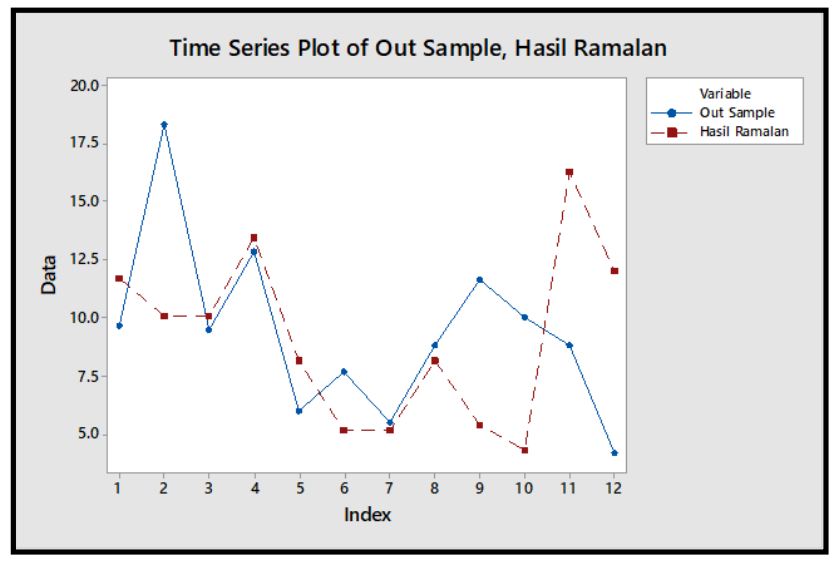

Gambar 2. Grafik data aktual dan data peramalan rata-rata curah hujan bulanan di Kota Bengkulu.

Gambar 2. menunjukkan bahwa dengan melakukan peramalan 12 periode ke depan, data hasil ramalan telah mendekati data aktual. 


\section{KESIMPULAN}

Permodelan rata-rata curah hujan bulanan Kota Bengkulu menggunakan data dari BMKG Bengkulu. Data memiliki pola berfluktiatif pada rataan dan ragam. Model SARIMA terbaik untuk data rata-rata curah hujan mingguan di Kota Bengkulu adalah model SARIMA $(0,1,1)(0,1,1)^{12}$ dengan nilai AIC 205,80 and SBC 210,91. Hasil peramalan 12 periode kedepan memperlihatkan ramalan telah mendekati pola data sebenarnya.

\section{UCAPAN TERIMA KASIH}

Terimakasih penulis ucapkan untuk BMKG atas data yang diberikan dan FMIPA atas kesempatan yang diberikan.

\section{DAFTAR PUSTAKA}

Agus, Samuel Haryanto, F., Puspitaningrum, D. and Ernawati (2015) 'Untuk Memprediksi Cuaca ( Studi Kasus: Kota Bengkulu )', Rekursif.

Geurts, M., Box, G. E. P. and Jenkins, G. M. (2006) 'Time Series Analysis: Forecasting and Control', Journal of Marketing Research. doi: 10.2307/3150485.

Huda, A. M. et al. (2012) 'PERAMALAN DATA CURAH HUJAN DENGAN SEASONAL AUTOREGRESSIVE INTEGRATED MOVING AVERAGE (SARIMA) DENGAN DETEKSI OUTLIER SEBAGAI UPAYA OPTIMALISASI PRODUKSI PERTANIAN DI KABUPATEN MOJOKERTO', in Seminar Nasional: Kedaulatan Pangan dan Energi.

Maulana, H. A. (2018) 'PEMODELAN DERET WAKTU DAN PERAMALAN CURAH HUJAN PADA DUA BELAS STASIUN DI BOGOR', Jurnal Matematika Statistika dan Komputasi. doi: 10.20956/jmsk.v15i1.4424.

Suhartono (2011) 'Time Series Forecasting by using Seasonal Autoregressive Integrated Moving Average: Subset, Multiplicative or Additive Model', Journal of Mathematics and Statistics. doi:

10.3844/jmssp.2011.20.27.

Tadesse, K. B. and Dinka, M. O. (2017) 'Application of SARIMA model to forecasting monthly flows in Waterval River, South Africa', Journal of Water and Land Development. doi: 10.1515/jwld-2017-0088. 